TERPENES

PINENES

EMISSION

SAMPLING
SPRUCE

SOFTWOOD

EXPOSURE

ANALYSIS

Open access manuscript version of Holzforschung 44 (1990) 449-452

Link to publisher

\title{
Ambient monoterpenes from stone groundwood pulp production
}

Ann-Margret Strömvall and Göran Petersson

Subsequent studies of terpene emissions were made for:

TMP and sulphite pulp mills

Barking of logs and pulpwood

$\underline{\text { Kraft pulp mills }}$ 
CHALMERS TEKNISKA HÖGSKOLA

Kemisk Miljövetenskap

\section{Ambient Monoterpenes from Stone Groundwood pulp production}

Ann-Margret Strömvall and Göran Petersson

Department of Chemical Environmental Science

Chalmers University of Technology

41296 Göteborg

August 1989

Manuscript to be published in Holzforschung, 1990 


\section{Summary}

Composition and ambient concentrations in air were studied for monoterpenes from stone groundwood production at a Swedish plant using exclusively pulp wood from Norwegian spruce. Field samples were taken on Tenax adsorption cartridges and analyzed by thermal desorption combined with temperature programmed capillary gas chromatography. The major monoterpenes emitted from the process were $\alpha$-pinene (54-598) and $\beta$-pinene (24-28\%). Limonene, 3-carene, $\beta$-phellandrene, camphene and myrcene (1-10\% each) followed in decreasing relative proportions. Total ambient monoterpene concentrations above $500 \mu \mathrm{g} / \mathrm{m}^{3}$ were assessed at ground level downwind from the emissions. Photo-oxidants formed in the monoterpene plumes are discussed with respect to forest damage and health hazards.

Keywords: monoterpenes, stone groundwood, mechanical pulp, Norwegian spruce, air pollution, emission plumes, photo-oxidants, gas chromatography 
Introduction

Ozone and other photo-oxidants are now regarded as a major factor behind the widespread forest decline not only in the US, but also in Europe. It is also recognized that emissions of hydrocarbons rather than nitrogen oxides give rise to enhanced ozone levels in local and regional anthropogenic emission plumes (Guderian Ed. 1985). The role of reactive biogenic hydrocarbons like terpenes in the formation of photo-oxidants has been studied and debated for a long time (Bufalini and Arnts Eds. 1981). Ambient monoterpenes from anthropogenic emissions have escaped similar attention. The present study is part of a program for the study of terpenes from forestry and the forest industry and of their 'environmental impact.

Stone groundwood pulp (Casey Ed. 1980) has long been and is still produced in million ton quantities, partly because of the high yield (up to 97\%) compared to chemical pulps. Technically, the terpenes are released in the grinding process at elevated temperatures. The wood in the grinding zone is heated to $100-200^{\circ} \mathrm{C}$ when the revolving 'water-cooled grindstone sets the wood fibres free. In sweden, stone groundwood is made from Norwegian spruce only, which facilitates a stringent characterization of the terpene emissions. 
Experimental

Industrial plant. The industry studied was Papyrus Molndal $\mathrm{AB}$ in the centre of the town of Mölndal south of Göteborg. More than 30000 tons yearly of dry groundwood pulp are produced from two adjacent stones (Great Northern - Tampella) which are normally operated both day and night. Terpene-containing steam is emitted through one pipe from each of the enclosed stones at a height of 5-10 metres. The pulp is used for cardboard production in another section of the plant. Farther away, paper is produced from chemical pulp inside the industrial complex.

Approximately $100000 \mathrm{~m}^{3}$ (solid volume) of pulp wood is required yearly. The softwood species used is exclusively Norwegian spruce (Picea abies) taken mostly from southern Sweden. Several thousand cubic metres of almost fresh unbarked and debarked pulp wood is stored in a wood-yard just south of the plant. Dry debarking is performed inside this wood-yard.

Sampling and analysis. Field sampling by adsorption was made on specially designed Tenax glass cartridges coupled to portable air sampling pumps. Samples were taken at ground level downwind from the emissions of monoterpenes. Sampling volumes were from 200 to $800 \mathrm{ml}$ and sampling times from 20 to 80 minutes. 
In the laboratory, thermal desorption was accomplished in the injector of a Carlo Erba gas chromatograph by the heated helium carrier gas. The fused silica capillary column $(25 \mathrm{~m} \times 0.33 \mathrm{~mm}$ i.d.) acted first as a cold trap and then as an analytical column. The stationary phase was a cross-linked BP-1 methyl silicone and the temperature was raised $2^{\circ} \mathrm{C}$ $\min ^{-1}$ linearly from $0^{\circ} \mathrm{C}$. Detection was by flame ionization and the response factor of monoterpenes was set equal to that determined for $\underline{n}$-heptane.

Further experimental details were given in a methodological study (Mattsson and Petersson 1982) with urban air pollutant applications. A modified application to monoterpenes in air was described in a recent study of biogenic terpenes in Scots pine forests (Petersson 1988).

$\underline{\text { Results and discussion }}$

The results are summarized in Tables 1 and 2 and in Figure 1, which also illustrates the chromatographic separation of the monoterpenes.

Plume concentrations. In Táble 1 results are given for samples selected as representative of ground-level downwind concentrations. As anticipated, the highest concentrations of more than $600 \mu \mathrm{g} / \mathrm{m}^{3}$ of total monoterpenes were recorded near the process emissions. 
Table 1. Concentration levels $\left(\mu \mathrm{g} / \mathrm{m}^{\prime \prime}\right)$ of monoterpenes in ambient air downwind from stone groundwood production.

\begin{tabular}{|c|c|c|c|c|}
\hline & \multicolumn{2}{|c|}{$\begin{array}{l}\text { grinding plume } \\
\text { near plant }\end{array}$} & \multirow{2}{*}{$\begin{array}{c}\begin{array}{c}\text { grinding plume } \\
\text { housing areab } \\
6 / 09 / 89\end{array} \\
92\end{array}$} & \multirow{2}{*}{$\begin{array}{c}\begin{array}{c}\text { plume from } \\
\text { woodyard } \\
5 / 30 / 89\end{array} \\
32\end{array}$} \\
\hline$\alpha$-pinene & 350 & 360 & & \\
\hline camphene & 13 & 15 & 3.1 & 1.5 \\
\hline$\beta$-pinene & 160 & 160 & 46 & 19 \\
\hline myrcene & 3.7 & 6.5 & - & 2.3 \\
\hline 3-carene & 24 & 32 & 6.7 & 4.5 \\
\hline B-phellandrene & 13 & 19 & 2.9 & 4.3 \\
\hline 11 monene & 22 & 39 & 4.2 & 3.8 \\
\hline$p$-cymene & 3.9 & 3.5 & 0.9 & 0.5 \\
\hline $\begin{array}{l}\text { Samples taken } \\
170^{\circ}\left(10^{\circ} \mathrm{C}\right) \text { and } \\
\text {-Sample taken } \\
10^{\circ} 0\left(15^{\circ} \mathrm{C}\right) \text {. } \\
\text { - Sample taken }\end{array}$ & $\begin{array}{l}\text { local } \\
30-23= \\
\text { uphi11 } \\
\text { side wo }\end{array}$ & $\begin{array}{l}\text { treet } 50 \\
\left.\text { (15० }{ }^{\circ} \mathrm{C}\right) \\
\text { rea } 150 \\
d \text {-yard } d x\end{array}$ & $\begin{array}{l}\text { In from the emis } \\
\text { from the emiss } \\
\text { uring debarking }\end{array}$ & $\begin{array}{l}\text { Ions } 16=0- \\
\text { ons } 09=0- \\
050-11=0(10\end{array}$ \\
\hline
\end{tabular}

Although the samples were taken along a street with local traffic, the concentration of the most abundant monoterpene $(\alpha$-pinene) was approximately 100 times higher than that of the most abundant alkylbenzene (toluene) from traffic emissions. The concentrations in the housing area should reflect the downwind exposure of the inhabitants from the grinding plume. 


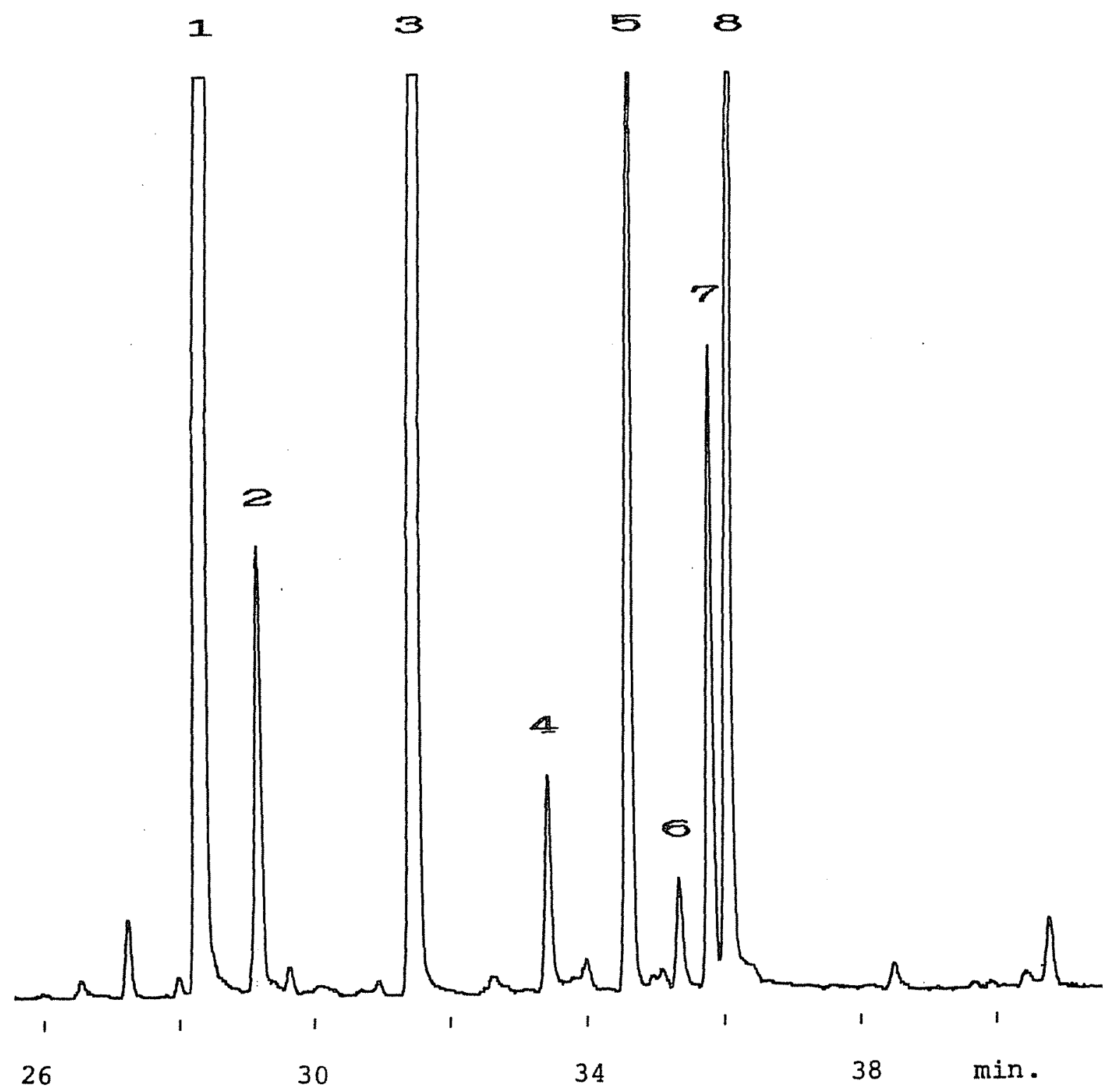

F1.gure 1 .

Gas chromatographic separation of monoterpenes in the near-plant plume from stone groundwood pulp production (1. $\alpha$-pinene;

2. camphene; 3. $\beta$-pinene; 4. myrcene; 5. 3-carene; 6. p-cymene;

7. $\beta$-phellandrene; 8. Iimonene). Sample taken $6 / 28 / 89^{2} 3^{\prime \prime}-23^{50}$. 
The samples were taken under conditions with turbulent air at positions where the smell of terpenes was strong. The fluctuating wind caused the sampling point to be not only below, but also often beside, the grindning plume centre. Consequently the concentrations in the centre of the plume are expected to be much higher than those given.

The concentrations just outside and above the wood-yard were much lower than those downwind of the grinding emissions. The wood-yard plume differs from the process plume not only by being approximately $100 \mathrm{~m}$ broad but also by reaching the sampling point all the time. The concentration ratios therefore do not necessarily reflect the emission ratios. In contrast to the grinding emissions, the wood-yard emissions are also expected to be strongly dependent on ambient parameters like temperature.

Composition of monoterpenes. In Table 2 the percentual composition of monoterpenes is given for samples taken downwind and near the process emissions. The individual night-time sample corresponds to the chromatogram of Figure 1 and is thought to be well representative. The narrow intervals for the five samples taken under somewhat differing conditions demonstrate a uniform composition of the emissions. 
Table 2. Monoterpenes emitted to air from the grinding process; reaction rates with ozone, and composition $(\%)$.

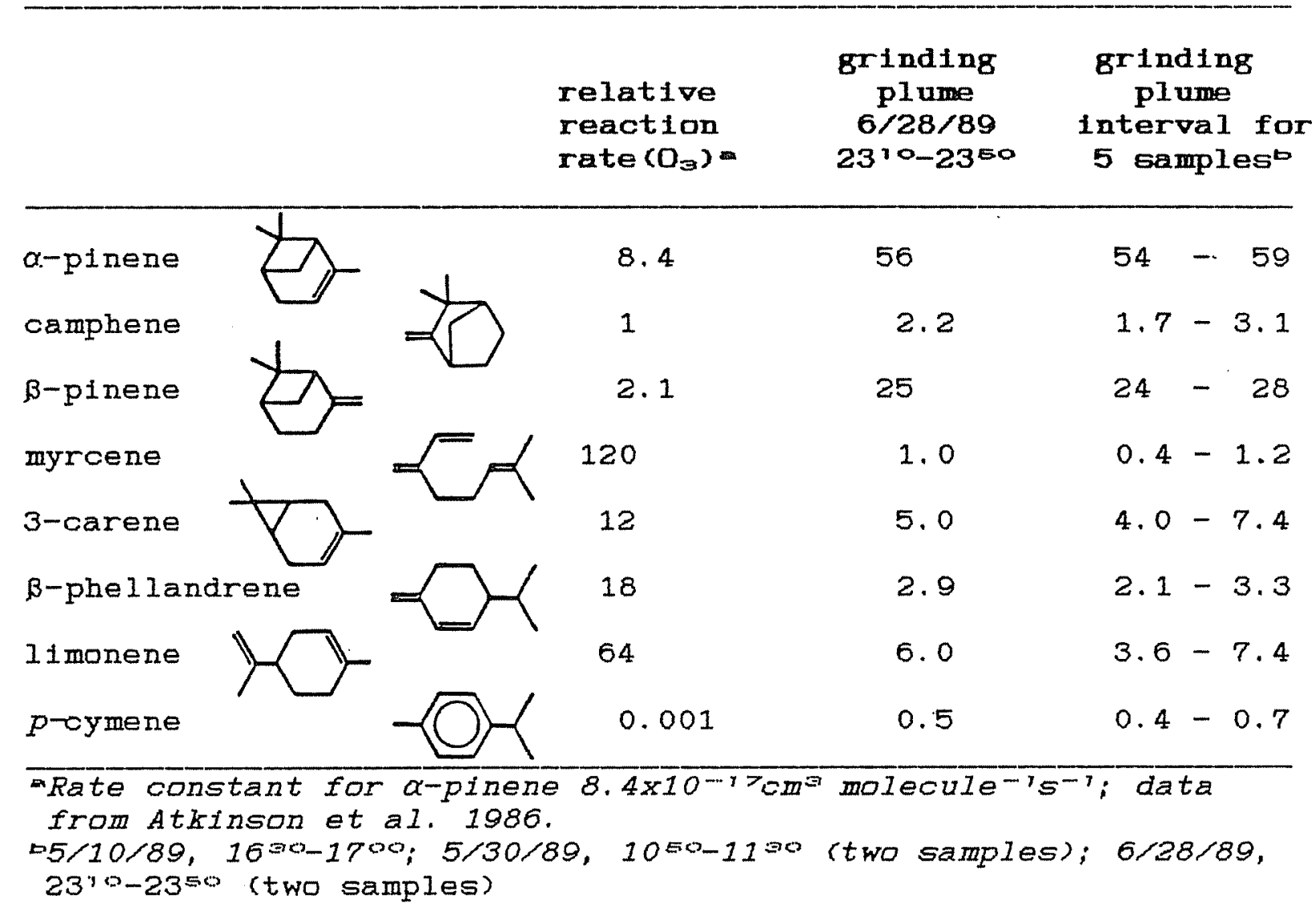

The content of the two predominant monoterpenes in the process plume was 54-59\% for $\propto$-pinene and 24-288 for $\beta$-pinene in all samples. The low content of 3-carene contrasts with the very high content of this terpene in the terpene-rich scots pine (Pinus sylvestris) which is the other major scandinavian softwood species. A limited portion of scots pine in the pulp wood may be used in certain groundwood plants and should then increase the content of 3-carene considerably. Iimonene, $\beta$-phellandrene, 
camphene and myrcene were present in proportions decreasing in this order. It is notable that the percentual content in needles of Picea abies is much higher for camphene, limonene and myrcene and lower for $\alpha$ - and $\beta$-pinene (Jüttner 1988 a). Retention data indicate that the compound eluting before $\alpha$-pinene (Fig.1) is the saturated monoterpene tricyclene shown to be present in needles. The content of this species was similar to that of the monoterpene-related alkylbenzene p-cymene. The small components appearing after limonene in the chromatogram are $\gamma$-terpinene and terpinolene. A study of emissions from plywood veneer drying (Crown et al. 1983) reports almost the same monoterpenes from wood of American softwood species but in varying proportions.

The same monoterpenes were also recorded in the emissions from the wood-yard but the composition was found to be less uniform. The results given in the fourth column of Table 1 correspond to an elevated proportion of myrcene and $\beta$-phellandrene compared to the process emissions. On other occasions only minor deviations in composition were found between the pulp wood plume and the process plume. The terpenes from the wood-yard are expected to be emitted from bark, debarked surfaces, and sawed cross-sections of the pulp wood. In contrast, the process emissions correspond to the monoterpene content in bark-free whole spruce wood. 
Photo-oxidant aspects. The rate-limiting initial reaction step during the day-light formation of photo-oxidants from monoterpenes involves reaction with the hydroxide radical (Atkinson et al. 1986) or with ozone (Atkinson and carter 1984). With the bicyclic monoterpenes, the two reactions compete, whereas the attack by ozone is normally more rapid for most monocyclic and for noncyclic monoterpenes (Table 2). During the spring and summer days critical with respect to formation of ozone and other photo-oxidants, the atmospheric lifetimes of the bicyclic monoterpenes may be less than one hour and that of myrcene less than 10 minutes. This means that elevated concentrations of photo-oxidants are obtained within shorter times and distances in monoterpene plumes than in most other types of hydrocarbon plumes. As a consequence, potential contributions to forest damage by the photo-oxidants formed are also expected to be found more locally and probably primarily within $0-50 \mathrm{~km}$ from the emissions.

Before net ozone production occurs in a monoterpene plume, the most reactive monoterpenes are expected to decrease ambient ozone concentrations in the plume by the initial reaction with ozone. The samples were taken under conditions not favouring ozone formation and in winds containing ozone-reducing No from traffic. Nevertheless, myrcene, and to some extent limonene, were lost from several samples taken in the housing area farther away from the emissions. This is 
probably partially explained by reaction with ambient ozone in the sampling cartridge (Jüttner 1988 b) and not only by rapid decomposition in the plume.

Under stagnant anticyclonic spring and summer periods, the reactive monoterpenes are expected to react to an appreciable extent within one or two kilometres from the emissions. Genotoxic reaction products obtained when nitrogen oxides are present in the air may then constitute a health hazard. A high mutagenic activity has been reported for gaseous products formed from alkenes in reaction-chamber experiments (Kleindienst et al. 1985).

The urban position of the industrial complex studied is particularly unfavourable with respect to potential health hazards. Nitrogen oxides are emitted both from the industry and from extensive traffic around the industrial area. The position of the monoterpene plume inside the much wider town plume may also be unfavourable with respect to air pollution outside the town. Photo-oxidant formation should be promoted by nitrogen oxides being continuously mixed into the central monoterpene plume.

Prevention of emissions. The Swedish monoterpene emissions to air from the stone groundwood process are approximately 1000 tons yearly assuming that 0.18 of the dry spruce wood is lost as monoterpenes. A 
similar estimate of the process emissions from the particular plant studied indicates 40 . tons yearly. Considering the photochemical reactivity of the monoterpenes, these large point source emissions of monoterpenes are not likely to be acceptable with respect to environmental protection.

The most environmentally attractive method to eliminate the emissions appears to be recovery of turpentine. The non-chemical groundwood process would give a different and more well-defined quality than the kraft pulping process from which large quantities of turpentine are recovered. The recovery of turpentine is facilitated by concentrated emission streams. Alternatively, the terpene emissions can be eliminated by a proper technique for combustion.

The emissions from storage and debarking of pulp wood are apparently more difficult to eliminate. On the other hand most of these emissions can easily be kept away from large emissions of nitrogen oxides and from densely populated areas. The reasons for debarking and storage outside urban and industrial areas are strongest during the spring and summer periods which are critical with respect to elevated emission levels as well as photo-oxidant formation. 
ACKNOWLEDGEMENTS

The authors are grateful to "The Swedish Society for Conservation of Nature" and to "The Swedish Council for Forestry and Agriculture Research" for supporting terpene research projects which made the present study possịle. 


\section{REFERENCES}

Atkinson, R. and W.P.L. Carter. 1984. Kinetics and mechanisms of the gas-phase reactions of ozone with organic compounds under atmospheric conditions. Chem. Rev. 84, 437-470.

Atkinson, R., S.M. Aschmann and J.N. Pitts, Jr. 1986. Rate constants for the gas-phase reactions of the $\mathrm{OH}$ radical with a series of monoterpenes at $294^{\circ} \mathrm{K}$. Int. J. Chem. Kinet. 18, 287-299.

Bufalini, J.J. and R.R. Arnts Eds. 1981. Atmospheric biogenic hydrocarbons. Ann Arbor Science. USA. Casey, J. P. Ed. 1980. Pulp and paper - chemistry and chemical technolgy, Volume 1, Wiley-Intersciense. Cronn, D.R., S.G. Truitt and M.J. Campbell. 1983. Chemical characterization of plywood veneer aryer emissions. Atmospheric Environment 17, 201-211. Guderian, R. Ed. 1985. Air pollution by photochemical oxidants. Springer-Verlag. GFR.

Jüttner, F. 1988a. Changes of monoterpene concentrations in needles of pollution-injured Picea abies exhibiting montane yellowing. Physiologica Plantarum 72, 48-56. Jüttner, F. 1988b. A cryotrap technique for the quantitation of monoterpenes in humid and ozonerich forest air. J. Chromatogr. 442, 157-163. Kleindienst, T.E., P.B. Shepson and E.O. Edney. 1985. The mutagenic activity of the products of propylene photooxidation. Environ. Sci. Technol. 19, 620-627. 
Mattsson, M. and G. Petersson. 1982. Trace analysis of hydrocarbons in air using standard gas chromatographic and personal sampling equipment. Intern. J. Environ. Anal. Chem. 11, 211-219. Petersson, G. 1988. High ambient concentrations of monoterpenes in a Scandinavian pine forest. Atmospheric Environment. 22, 2617-2619. 